\title{
ShRNA-mediated gene silencing of AHR promotes the differentiation of P19 mouse embryonic carcinoma cells into cardiomyocytes
}

\author{
CHUN ZHU $^{1 *}$, YU-LIN CHEN $^{1 *}$, XUE-JIE WANG ${ }^{2}$, XIAO-SHAN HU ${ }^{2}$, ZHANG-BIN YU $^{1}$ and SHU-PING HAN ${ }^{1}$ \\ ${ }^{1}$ State Key Laboratory of Reproductive Medicine, Department of Pediatrics, Nanjing Maternity and Child Health Care Hospital \\ Affiliated to Nanjing Medical University; ${ }^{2}$ Institute of Pediatrics, Nanjing Medical University, Nanjing 210029, P.R. China
}

Received December 16, 2011; Accepted May 31, 2012

DOI: $10.3892 / \mathrm{mmr} .2012 .941$

\begin{abstract}
The aryl hydrocarbon receptor (AHR) is a basic helix-loop-helix (bHLH) transcription factor that is activated by environmental contaminants including polychlorinated biphenyls (PCBs). The AHR affects a variety of processes that are involved in cell growth and differentiation. In this study, we constructed a P19 embryonic carcinoma cell line with AHR gene silencing using the vector-based approach of short hairpin (sh)RNA interference that allows cells to differentiate into cardiac myocytes when treated with dimethyl sulfoxide (DMSO). The expression levels of the cardiac developmentspecific GATA4 and $N k x 2.5$ genes were measured using real-time quantitative polymerase chain reaction (qPCR). Our data showed that the expression levels of the GATA4 and $N k x 2.5$ genes were increased in the AHR-silenced P19 cells compared with the control groups. Four critical genes (ARNT, CYP1A1, GSK3 $\beta$ and $\beta$-catenin) expressed in the AHR and in the Wnt signaling pathway were also measured by qPCR. We found that the expression levels of ARNT, CYPlAl and $\beta$-catenin were suppressed, whereas $G S K 3 \beta$ expression was elevated in the AHR-silenced P19 cells. Therefore, it is possible that the silencing of AHR promotes the differentiation of P19 cells through the AHR and Wnt signal transduction pathway.
\end{abstract}

Correspondence to: Dr Shu-Ping Han, State Key Laboratory of Reproductive Medicine, Department of Pediatrics, Nanjing Maternity and Child Health Care Hospital Affiliated to Nanjing Medical University, Nanjing 210029, P.R. China

E-mail: shupinghan@njmu.edu.cn

Dr Zhang-Bin Yu, State Key Laboratory of Reproductive Medicine, Department of Pediatrics, Nanjing Maternity and Child Health Care Hospital Affiliated to Nanjing Medical University, Nanjing 210029, P.R. China

E-mail: zhangbinyu@njmu.edu.cn

*Contributed equally

Key words: aryl hydrocarbon receptor, short hairpin RNA, AHR and Wnt signal transduction pathway, heart development

\section{Introduction}

The heart is the first organ to form in vertebrate embryogenesis (1). In vertebrates, the survival of the developing embryo depends on the heart and the circulatory systems, therefore cardiac abnormalities not only cause miscarriage and stillbirth, but also seriously affect the quality of life after birth (2). The heart is extremely sensitive to embryonic environmental changes during development. Certain physical, chemical and biological contaminants are known to contribute to cardiovascular disease $(3,4)$. The current study shows that exposure to persistent organic pollutants, such as polychlorinated biphenyls (PCBs), is significantly correlated with heart disease $(5,6)$. In China, PCB contamination has become a serious environmental problem. For example, in Jiangsu Province the concentration of PCBs in some surface water has exceeded the standard (20 ng/l) for the 'Environmental Quality Standard for Surface Water' (7). Total PCB concentration in human adipose tissue ranged from 4.1 to $125 \mathrm{ng} / \mathrm{g}$ lipid (mean $32.8 \mathrm{ng} / \mathrm{g}$ lipid), which significantly exceeds the mean total World Health Organization (WHO) toxicity equivalent (TEQ) values for PCBs in human adipose tissue, which is $16.2 \mathrm{pg} / \mathrm{g}$ lipid (8). Studies have also demonstrated that PCBs may pass through the placenta to the fetus in mothers who have been exposed before and during pregnancy $(9,10)$.

The AHR belongs to the basic helix-loop-helix Per-Arnt-Sim family of transcriptional regulators. Several studies have shown that members of this family play key roles in a broad range of biological functions and that the biochemical and toxicological effects of PCBs act through the AHR pathway $(11,12)$. However, little is known about the underlying effects of the AHR during the differentiation of embryonic carcinoma cell line P19 into cardiomyocytes.

In this study, we constructed two short hairpin (sh)RNA plasmid vectors against AHR that were capable of persistently generating small interfering (si)RNA in cells. We transfected these vectors into the P19 cells to determine the effects of AHR gene silencing on their differentiation. Furthermore, we examined the expression levels of four critical genes (ARNT, CYPIA1, GSK $3 \beta$ and $\beta$-catenin), and determined which are components of the AHR and Wnt signaling pathways using quantitative polymerase chain reaction (qPCR). 


\section{Materials and methods}

Cell culture. P19 cells were obtained from the American Type Culture Collection (ATCC, Manassas, VA, USA). The cells were cultured in $\alpha$-minimal essential medium ( $\alpha$-MEM; Gibco-BRL, Grand Island, NY, USA) containing $10 \%$ fetal bovine serum (FBS; Gibco-BRL), $100 \mathrm{U} / \mathrm{ml}$ penicillin and $100 \mu \mathrm{g} / \mathrm{ml}$ streptomycin in bacteriological dishes in an atmosphere of $5 \% \mathrm{CO}_{2}$ in air at $37^{\circ} \mathrm{C}$. Embryoid bodies (EB) were transferred to $10-\mathrm{cm}$ bacterial dishes that contained $15 \mathrm{ml}$ $\alpha$-MEM supplemented with $1 \%$ DMSO (Sigma, St. Louis, MO, USA), $10 \%$ FBS, $100 \mathrm{U} / \mathrm{ml}$ penicillin and $100 \mu \mathrm{g} / \mathrm{ml}$ streptomycin to induce cardiac differentiation, and then cultured for $96 \mathrm{~h}$. The EBs were then collected and transferred to 6-cm bacterial dishes supplemented with $\alpha$-MEM containing $10 \%$ FBS for an additional 6 days. Cell morphological changes during the growth and differentiation of P19 were observed under an inverted microscope (Nikon, Tokyo, Japan).

Construction of shRNA expression vector for AHR. Two target DNA fragments were designed and constructed for AHR based on shRNA design, enzyme insertion sites in the pGPU6-GFP-Neo expression vector and the AHR exons (GenBank accession number: NM_013464.4) as cited in GenBank. The sequences of the primers used were: shRNA1 sense: 5'-CAGAGCGTATATGAGCTCATCCATA-3'; and antisense: 5'-GTCTCGCATATACTCGAGTAGGTAT-3'; shRNA2 sense:5'-CCTCCACAGGCAGCAGTCTATTATA-3'; and antisense: 5'-GGAGGTGTCCGTCGTCAGATAATAT-3'. Another unrelated sequence was used as the control. No homologous sequence was found by BLAST analysis. Loopstem structure was a non-homologous base (TTCAAGAGA), which was non-complementary to AHR. Enzyme insertion sites for BbsI and BamHI were constructed into the ends of the oligonucleotide fragments, and the specificity of constructed oligonucleotides strands was analyzed by the BLAST program. The primer sequences were as follows: shRNA1 sense: 5'-CACCGCAGAGCGTATATGAGCTCATCCATATTCAAG AGATATGGATGAGCTCATATACGCTCTGTTTTTTG-3'; and antisense: 5'-GATCCA A A A ACAGAG CGTATATGAGCTCATCCATATCTCTTGATATGGATGAG CTCATATACGCTCTGC-3'; shRNA2 sense: 5'-CACCGCCTCCACAGGCAGCAGTCTATTATATTCAAG AGATATAATAGACTGCTGCCTGTGGAGGTTTTTTG-3'; and antisense: 5'-GATCCAAAAAACCTCCACAGG CAGCAGTCTATTATATCTCTTGAATATAATAGACTGC TGCCTGTGGAGGC-3'. Sense and antisense oligonucleotides were annealed to generate a double-stranded oligonucleotide, and the annealed shRNA oligonucleotide fragment template was inserted into the pGPU6-GFP-Neo vector using T4 DNA ligase. The recombinant plasmid was then transformed into competent bacillus Escherichia coli, and the bacteria were cultured overnight in LB medium that contained kanamycin. Recombinant plasmids were extracted, purified and cut using restriction enzymes BbsI, BamHI and PstI in order to identify the correct fragments.

Plasmid transfection. P19 cells were digested with trypsin and seeded into 6-well plates. When the density of the cells on the slide reached $80-90 \%$ confluence they were transfected in four groups: the first group was the blank control, the second was the negative control, the third was the shRNA1 group and the fourth was the shRNA2 group. Transfection was performed in accordance with the manufacturer's instructions. Briefly, P19 cells were seeded into 6 -well plates at a density of $2.5 \times 10^{5}$ cells/ well and cultured for $24 \mathrm{~h}$. Lipofectamine 2000 (Invitrogen, Carlsbad, CA, USA) was mixed with Opti-MEM I medium, shRNA expression vectors were added to the solution and the cells were incubated at room temperature for 20-25 min. The transfection mixture was added to each well with $600 \mu \mathrm{l}$ FBS-free $\alpha$-MEM medium. The cells were incubated at $37^{\circ} \mathrm{C}$ for 4-6 h, and the medium was changed. $\alpha$-MEM medium $(1.5 \mathrm{ml})$ containing $10 \%$ FBS was added and the cells were incubated for another $24 \mathrm{~h}$.

RNA and real-time $q P C R$. Total RNA was extracted from cells using TRIzol reagent according to the manufacturer's instructions (Invitrogen). Total RNA $(1 \mu \mathrm{g})$ was transcribed to cDNA using M-MLV reverse transcriptase. Real-time qPCR reactions were carried out using an MX3000 real-time instrument (Stratagene, Cedar Creek, TX, USA). Each PCR amplification was performed in triplicate, using the following conditions: samples were incubated at $95^{\circ} \mathrm{C}$ for $3 \mathrm{~min}$ for initial denaturation, and then subjected to 40 PCR cycles. Each PCR cycle consisted of $95^{\circ} \mathrm{C}$ for $30 \mathrm{sec}$ and $62^{\circ} \mathrm{C}$ for $40 \mathrm{sec}$. Additionally, normalization to the housekeeping gene glyceraldehyde 3-phosphate dehydrogenase (GAPDH) was performed. The primer sequences used are listed in Table I.

Statistical analysis. Values are shown as the mean \pm standard deviation (SD). Statistical analyses were performed using one-way analysis of variance (ANOVA) and t-tests or Student'stests with a correction for multiple comparisons. $\mathrm{P}<0.05$ was considered to indicate a statistically significant result.

\section{Results}

Identification of enzyme digestion. AHR-targeted shRNA expression vectors were cut using PstI. A DNA band of 5,180 bp was able to be digested, which indicated that the target gene segment AHR had been inserted into pGPU6-GFP-Neo vector (Fig. 1).

Observation of transfection results. Transfection was carried out using Lipofectamine 2000 (Invitrogen) according to the manufacturer's instructions. After $48 \mathrm{~h}$, green fluorescence was observed in transfected cells under the fluorescence microscope, and the transfection rate was found to be approximately $50 \%$ (Fig. 2).

shRNA targeting AHR inhibited AHR mRNA expression in P19 cells. We used real-time qPCR to confirm the efficiency of shRNA silencing on AHR expression. No statistically significant difference was found in AHR mRNA expression between the mock treatment group and the blank control group. Moreover, the two shRNA groups showed varying degrees of inhibitory effect (Fig. 3). Therefore, the AHR-targeted shRNA expression vectors were selected for subsequent experiments. 
Table I. Primers used for real-time polymerase chain reaction (PCR).

\begin{tabular}{|c|c|c|}
\hline Gene name & Sequences $\left(5^{\prime}-3^{\prime}\right)$ & Product length (bp) \\
\hline AHR & $\begin{array}{l}\text { F: ATGGAGAGGTGCTTCAGGTGCCG } \\
\text { R: ATGGAGGGTGGCTGAAGTGGAGT }\end{array}$ & 185 \\
\hline GATA4 & $\begin{array}{l}\text { F: CCTGCGGCCTCTACATGA } \\
\text { R: AGGGTCTCACCAGCAGGA }\end{array}$ & 136 \\
\hline $\mathrm{Nkx} 2.5$ & $\begin{array}{l}\text { F: CCTGCGGCCTCTACATGA } \\
\text { R: AGGGTCTCACCAGCAGGA }\end{array}$ & 222 \\
\hline ARNT & $\begin{array}{l}\text { F: GACAGACCACAGGACAGTTCC } \\
\text { R: AGCATGGACAGCATTTCTTGAA }\end{array}$ & 172 \\
\hline CYP1A1 & $\begin{array}{l}\text { F: GGTTAACCATGACCGGGAACT } \\
\text { R: TGCCCAAACCAAAGAGAGTGA }\end{array}$ & 122 \\
\hline GSK3 $\beta$ & $\begin{array}{l}\text { F: TGGCAGCAAGGTAACCACAG } \\
\text { R: CGGTTCTTAAATCGCTTGTCCTG }\end{array}$ & 189 \\
\hline$\beta$-catenin & $\begin{array}{l}\text { F: ATGGAGCCGGACAGAAAAGC } \\
\text { R: CTTGCCACTCAGGGAAGGA }\end{array}$ & 108 \\
\hline GAPDH & $\begin{array}{l}\text { F: TTCACCACCATGGAGAAGGC } \\
\text { R: GGCATGGACTGTGGTCATGA }\end{array}$ & 237 \\
\hline
\end{tabular}

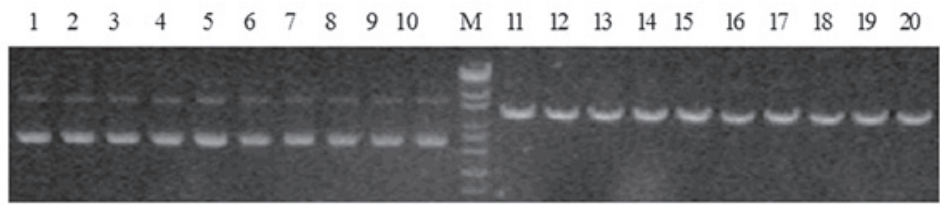

Figure 1. Restrictive enzyme incision analysis for pGPU6-GFP-Neo-AHR shRNA plasmid using RT-PCR. Lanes 1-5, pGPU6-GFP-Neo-AHR shRNA1 plasmid was cut off by PstI. Lanes 6-10, pGPU6-GFP-Neo-AHR shRNA2 plasmid was cut off by PstI. Lanes 11-15, pGPU6-GFP-Neo-AHR shRNA1 plasmid was cut off by BamHI. Lanes 16-20, pGPU6-GFP-Neo-AHR shRNA2 plasmid was cut off by BamHI. M, DNA marker.
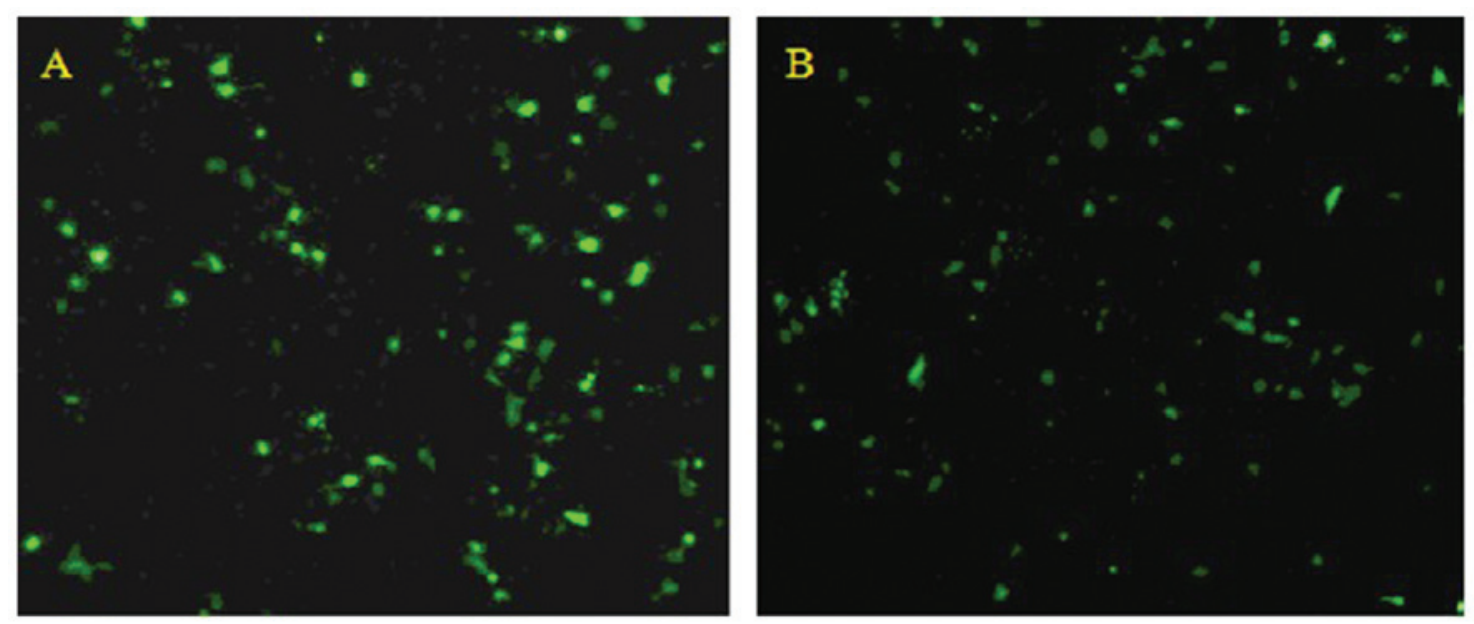

Figure 2. The expression of GFP (green fluorescent protein) in P19 cells transfected with pGPU6-GFP-Neo-AHR shRNA plasmids under a fluorescent microscope. (A) P19 cells transfected with pGPU6-GFP-Neo-AHR shRNA1 plasmids for 48 h. (B) P19 cells transfected with pGPU6-GFP-Neo-AHR shRNA2 plasmids for $48 \mathrm{~h}$.

Expression of marker gene during P19 cell differentiation. The GATA4 and Nkx2.5 genes are expressed in cardiomyocytes as cardiac-specific genes; therefore, their expression was examined during P19 cell differentiation. GATA4 and Nkx2.5 gene expression levels were upregulated during heart development (from day 0 to day 10) and the expression levels were 


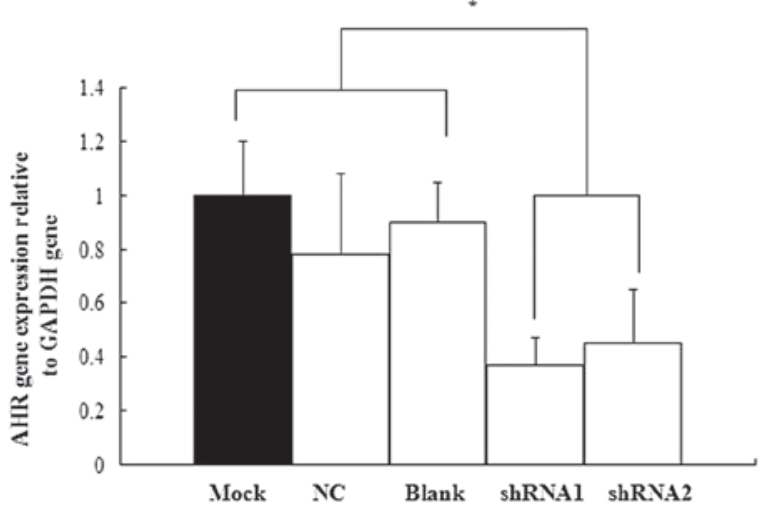

Figure 3. Effect of shRNA expression vectors on AHR mRNA expression in P19 cells. AHR mRNA inhibition rate for shRNA1 and shRNA2 was 64 and $52 \%$, respectively, compared with the control group $(\mathrm{p}<0.05)$.

increased on day 10 in the AHR-silenced P19 cells compared with the control cells (Fig. 4).

A

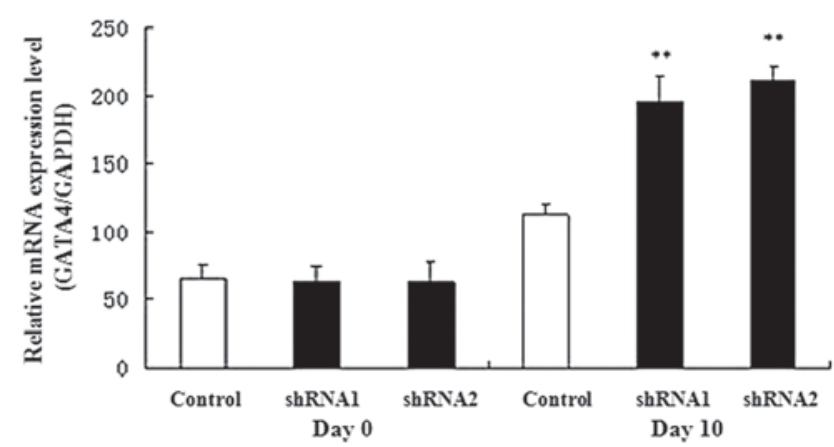

Expression of AHR and Wnt signal transduction genes during P19 cell differentiation. We detected the expression levels of AHR signal transduction-related genes, including ARNT and $C Y P 1 A$, using qPCR. On day 10 expression levels of $A R N T$ and CYP1A1 were lower in the AHR-silenced P19 cells than in the controls (Fig. 5). We also determined the expression levels of genes $G S K 3 \beta$ and $\beta$-catenin involved in the Wnt signal transduction pathway. Results from qPCR revealed that $\beta$-catenin was suppressed, whereas $G S K 3 \beta$ was increased, in the AHR-silenced P19 cells (Fig. 6).

\section{Discussion}

RNA interference (RNAi) is one of the most powerful technologies for the specific blocking of gene expression (13). In this study, we successfully transfected two shRNAs that targeted the AHR gene into P19 cells. The results showed that AHR mRNA expression examined in the shRNA1 and shRNA2 groups was inhibited by approximately 64 and $52 \%$, respectively, compared with the control group.

B

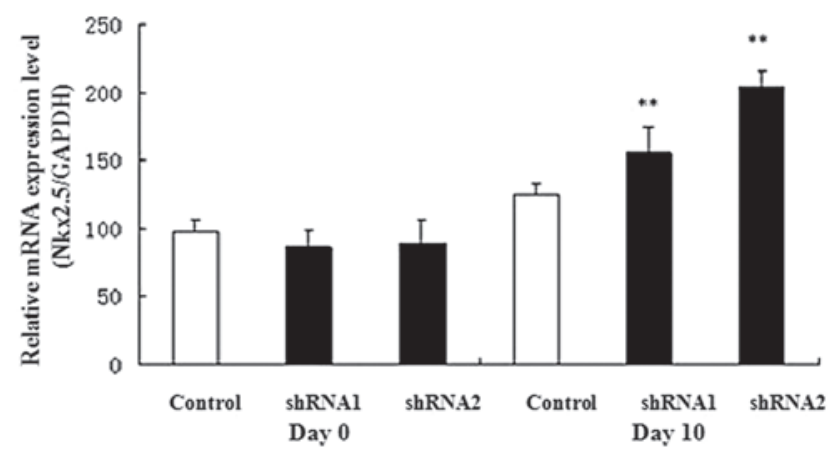

Figure 4. Expression of GATA4 and $N k x 2.5$ during P19 cell differentiation by real-time quantitative PCR (qPCR). (A and B) No difference in the expression levels of GATA4 and Nkx2.5 genes was found between AHR-silencing P19 cells and the controls on day 0. On day 10, GATA4 and Nkx2.5 expression levels were markedly higher in the AHR-silencing P19 cells than in the controls. Data resulted from three independent experiments $\left({ }^{* *} \mathrm{p}<0.01\right)$.

A

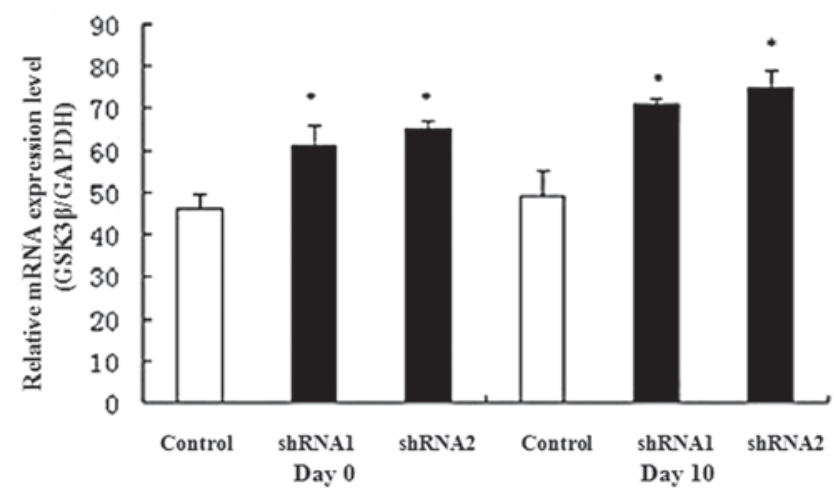

$\mathbf{B}$

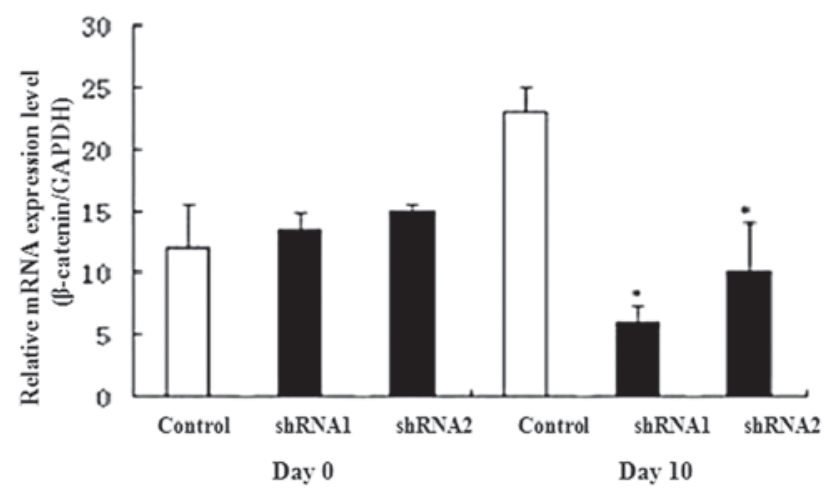

Figure 5. Expression of Wnt signal transduction genes, GSK3 $\beta$ and $\beta$-catenin, during P19 cell differentiation by real-time quantitative PCR (qPCR). GSK3 $\beta$ gene expression was higher in the AHR-silencing P19 cells than in the controls (days 0 and 10) (A). No difference in expression levels of the $\beta$-catenin gene was found between AHR-silencing P19 cells and the controls on day 0. On day 10, $\beta$-catenin expression was much lower in the AHR-silencing P19 cells than in the controls. Data are from three independent experiments $\left({ }^{*} \mathrm{p}<0.05\right)$. 

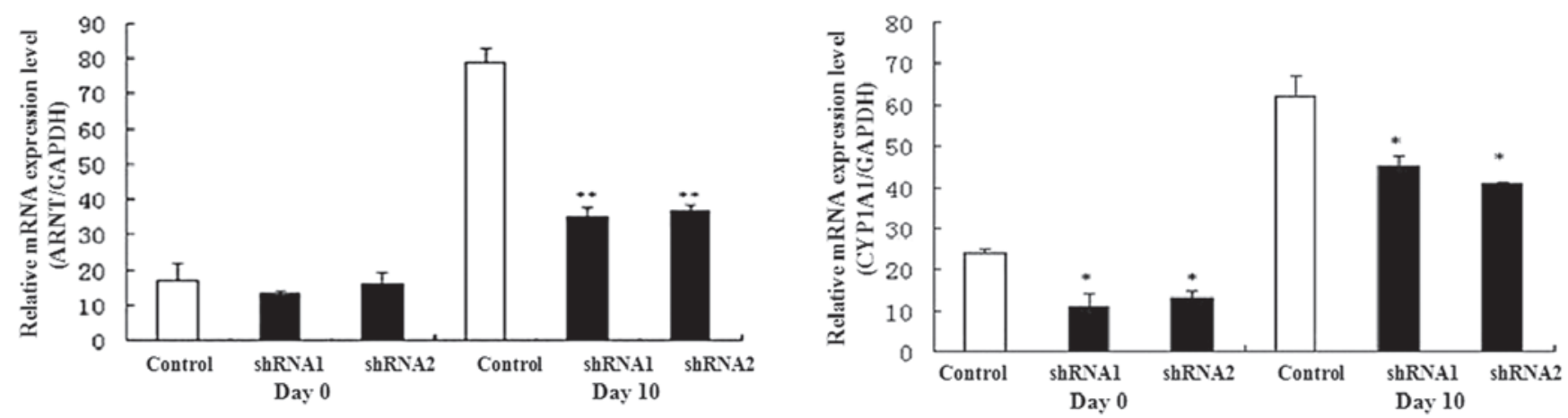

Figure 6. Expression of AHR signal transduction genes during P19 cell differentiation by real-time quantitative PCR (qPCR). No difference in expression levels of ARNT gene was found between AHR-silencing P19 cells and the controls on day 0. On day 10, ARNT was markedly lower in the AHR-silencing P19 cells than in the controls (A). CYP1A1 was much lower in the AHR-silencing P19 cells than in the controls (days 0 and 10). Data are from three independent experiments $\left({ }^{*} \mathrm{p}<0.05,{ }^{* *} \mathrm{p}<0.01\right)$.

Using shRNA, we found that the gene silencing of AHR caused the expression levels of two myocardial cell differentiation-related genes (GATA4 and $N k x 2.5)$ to be elevated. In addition, real-time qPCR revealed that the expression of $A R N T$, CYPIAl and $\beta$-catenin was suppressed, but the expression of $G S K 3 \beta$ was increased in the AHR-silenced P19 cells. These results suggest that the silencing effect of AHR promotes the differentiation of P19 mouse embryonic carcinoma cells into cardiomyocytes. The Wnt signal transduction pathway may be responsible for the effect of silencing AHR in P19 cells.

Findings of studies have shown that PCBs are one of the most ubiquitous contaminants that are important in the development of cardiovascular disease $(14,15)$. It is generally believed that the effects of PCBs are mediated through the AHR pathway (16). Lund et al found that knockout of the $A H R$ gene in mice disrupted cardiovascular homeostasis, which caused significant cardiac hypertrophy and elevated levels of expression of cardiovascular markers (17). In this study, we also found that the expression of cardiac development-specific genes was induced in the AHR-silenced P19 cells. These results suggested that the AHR signaling pathway is crucial in cardiovascular development programs.

Wnt protein and its signaling pathways are among the most intensely studied pathways in biology (18). Previous studies have suggested that the Wnt proteins are capable of inducing cell proliferation, differentiation and maturation (19). The canonical Wnt signaling pathway may be manipulated to regulate the expansion and differentiation of cardiac progenitor cells, and Wnt signaling was found to be essential to the development of the heart in mammals $(20,21)$. In this study, the expression of the critical AHR signaling pathway genes (AHR, ARNT and CYPIAI) was reduced in the AHR-silenced P19 cells. In addition, the $\beta$-catenin expression level was decreased but $G S K 3 \beta$ was increased in the AHR-silenced P19 cells during heart development. Taking into account the fact that AHR activation may inappropriately activate the Wnt signaling pathway and that there is crosstalk between AHR and Wnt signaling (22), we suggest that the silencing of AHR inhibited the differentiation of embryonic carcinoma P19 cells, possibly through the Wnt signaling transduction pathway.
In conclusion, we constructed a shRNA expression vector for AHR. Findings of the present study showed that the expression levels of GATA4 and $N k x 2.5$ genes were increased in the AHR-silenced P19 cells. We also found that $A R N T$, CYPIAl and $\beta$-catenin were suppressed, whereas $G S K 3 \beta$ was elevated, in the AHR-silenced P19 cells. However, the exact mechanisms of how the AHR and Wnt signaling pathways affect the differentiation of P19 cells into cardiac myocytes should be investigated.

\section{Acknowledgements}

This study was supported by a grant from the National Natural Science Foundation of China (no. 30973213) .

\section{References}

1. Olson EN: Gene regulatory networks in the evolution and development of the heart. Science 313: 1922-1927, 2006.

2. Hsiao SM, Wu MH, Jou HJ, Lee CN, Shyu MK, Shih JC and Hsieh FJ: Outcome for fetuses with prenatally detected congenital heart disease and cardiac arrhythmias in Taiwan. J Formos Med Assoc 106: 423-431, 2007.

3. Hennig B, Meerarani P, Slim R, Toborek M, Daugherty A, Silverstone AE and Robertson LW: Proinflammatory properties of coplanar PCBs: in vitro and in vivo evidence. Toxicol Appl Pharmacol 181: 174-183, 2002.

4. Pelclová D, Urban P, Preiss J, Lukás E, Fenclová Z, Navrátil T, Dubská Z and Senholdová Z: Adverse health effects in humans exposed to 2, 3, 7, 8-tetrachlorodibenzo- $p$-dioxin (TCDD). Rev Environ Health 21: 119-138, 2006.

5. DeWitt JC, Millsap DS, Yeager RL, Heise SS, Sparks DW and Henshel DS: External heart deformities in passerine birds exposed to environmental mixtures of polychlorinated biphenyls during development. Environ Toxicol Chem 25: 541-551, 2006.

6. Majkova Z, Smart E, Toborek M and Hennig B: Up-regulation of endothelial monocyte chemoattractant protein-1 by coplanar PCB77 is caveolin-1-dependent. Toxicol Appl Pharmacol 237: 1-7, 2009.

7. Hong Y, Chunhong Z and Xiaoxiong Z: Investigation of pollution characteristics of polychlorinated biphenyls in the typical drinking water sources in Jiangsu Province, China. Environ Monit Assess 158: 573-579, 2009.

8. Shen H, Shen H, Han J, Tie X, Xu W, Ren Y and Ye C: Polychlorinated dibenzo- $p$-dioxins/furans and polychlorinated biphenyls in human adipose tissue from Zhejiang Province, China. Chemosphere 74: 384-388, 2009. 
9. Suzuki G, Nakano M and Nakano S: Distribution of PCDDs/ PCDFs and co-PCBs in human maternal blood, cord blood, placenta, milk, and adipose tissue: dioxins showing high toxic equivalency factor accumulate in the placenta. Biosci Biotechnol Biochem 69: 1836-1847, 2005.

10. Shen H, Shen H, Main KM, Virtanen HE, Damggard IN, Haavisto AM, Kaleva M, Boisen KA, Schmidt IM, Chellakooty M, Skakkebaek NE, Toppari J and Schramm KW: From mother to child: investigation of prenatal and postnatal exposure to persistent bioaccumulating toxicants using breast milk and placenta biomonitoring. Chemosphere 67: S256-S262, 2007.

11. Liu S and Piatigorsky J: Regulation of mouse small heat shock protein $\alpha b$-crystallin gene by aryl hydrocarbon receptor. PLoS One 6: e17904, 2011.

12. Shimada T, Sugie A, Shindo M, Nakajima T, Azuma E, Hashimoto $\mathrm{M}$ and Inoue $\mathrm{K}$ : Tissue-specific induction of cytochromes P450 1A1 and 1B1 by polycyclic aromatic hydrocarbons and polychlorinated biphenyls in engineered C57BL/6J mice of arylhydrocarbon receptor gene. Toxicol Appl Pharmacol 187: $1-10,2003$

13. Manoharan M: RNA interference and chemically modified small interfering RNAs. Curr Opin Chem Biol 8: 570-579, 2004.

14. Han SG, Eum SY, Toborek M, Smart E and Hennig B: Polychlorinated biphenyl-induced VCAM-1 expression is attenuated in aortic endothelial cells isolated from caveolin-1 deficient mice. Toxicol Appl Pharmacol 246: 74-82, 2010.

15. Hennig B, Reiterer G, Majkova Z, Oesterling E, Meerarani P and Toborek M: Modification of environmental toxicity by nutrients: implications in atherosclerosis. Cardiovasc Toxicol 5: 153-160, 2005.
16. Grimes AC, Erwin KN, Stadt HA, Hunter GL, Gefroh HA, Tsai HJ and Kirby ML: PCB126 exposure disrupts zebrafish ventricular and branchial but not early neural crest development. Toxicol Sci 106: 193-205, 2008.

17. Lund AK, Peterson SL, Timmins GS and Walker MK: Endothelin-1-mediated increase in reactive oxygen species and NADPH oxidase activity in hearts of aryl hydrocarbon receptor (AhR) null mice. Toxicol Sci 88: 265-273, 2005.

18. Shevtsov SP, Haq S and Force T: Activation of beta-catenin signaling pathways by classical G-protein-coupled receptors: mechanisms and consequences in cycling and non-cycling cells. Cell Cycle 5: 2295-2300, 2006.

19. Nakamura T, Sano M, Songyang Z and Schneider MD: A Wntand beta-catenin-dependent pathway for mammalian cardiac myogenesis. Proc Natl Acad Sci USA 100: 5834-5839, 2003.

20. Kwon C, Arnold J, Hsiao EC, Taketo MM, Conklin BR and Srivastava D: Canonical Wnt signaling is a positive regulator of mammalian cardiac progenitors. Proc Natl Acad Sci USA 104: 10894-10899, 2007.

21. Ai D, Fu X, Wang J, Lu MF, Chen L, Baldini A, Klein WH and Martin JF: Canonical Wnt signaling functions in second heart field to promote right ventricular growth. Proc Natl Acad Sci USA 104: 9319-9324, 2007.

22. Mathew LK, Sengupta SS, Ladu J, Andreasen EA and Tanguay RL: Crosstalk between AHR and Wnt signaling through R-Spondin1 impairs tissue regeneration in zebrafish. FASEB J 22: 3087-3096, 2008. 